\title{
Assessing the Relationship Between BPM Maturity and the Success of Organizations
}

\author{
Joana Pinto ${ }^{1}$ [0000-0001-8477-5126] and Vitor Duarte dos Santos ${ }^{1}$ [0000-0002-4223- \\ 7079] \\ ${ }^{1}$ Universidade Nova de Lisboa - Information Management Systems School, Lisbon, \\ Portugal m20170209@isegi.unl.pt
}

This is the Author Peer Reviewed version of the following chapter published by Springer:

Pinto, J., \& dos Santos, V. D. (2020). Assessing the relationship between bpm maturity and the success of organizations. In R. Silhavy (Ed.), Applied Informatics and Cybernetics in Intelligent Systems: Proceedings of the 9th Computer Science On-line Conference, CSOC 2020 (pp. 108-126). (Advances in Intelligent Systems and Computing; Vol. 1226 AISC). Springer. https://doi.org/10.1007/978-3-030-51974$\underline{210}$

\section{(c) (1) (8)}

This work is licensed under a Creative Commons Attribution-NonCommercial 4.0 International License. 


\title{
Assessing the Relationship Between BPM Maturity and the Success of Organizations
}

\author{
Joana Pinto ${ }^{1[0000-0001-8477-5126]}$ and Vitor Duarte dos Santos $^{1 \text { [0000-0002-4223-7079] }}$ \\ ${ }^{1}$ Universidade Nova de Lisboa - Information Management Systems School, Lisbon, Portugal \\ m20170209@isegi.unl.pt
}

\begin{abstract}
.
For the past decades, organizations have been investing heavily in BPM projects in the hope of improving their competitive advantage in an increasingly complex environment. However, although it is believed that the higher the level of BPM maturity the greater the success of the organization, experience shows that this relationship is not always possible to prove.

The purpose of this study is to help clarify the relationship between the level of BPM maturity and the success of an organization. This was done through the implementation of a case study-based research within a global company, focusing on the shared services organization.

An analysis of the existing BPM maturity models and its level of coverage of BPM core areas was conducted to select the most suitable BPM maturity model to conduct the assessment of the current BPM maturity level. It was also established a framework to characterize the success of an organization. These two inputs, along with information gathered to understand implemented process improvements, were the basis for conducting the research.

Results show a successful organization, with a high maturity level according to the BPM OMG maturity model, that has been investing in continually improving its processes with a strong focus on digital transformation. The identified benefits from a high level of BPM maturity, namely improved productivity, cost reduction, error \& risk prevention, higher agility, employee upskilling and knowledge retention, were shown to have a positive influence in the majority of the dimensions used to characterize the success of the organization.
\end{abstract}

Keywords: Business Process Management Maturity, Success of Organizations, Shared Services.

\section{Introduction}

\subsection{Background}

Since the first industrial revolution, companies have been focusing on continuously improving their productivity by introducing new technical innovations, as well as by (re)organizing the work in a way to become more effective and efficient [1]. In this context, over the past decades, companies became aware on the benefits of being 
process oriented as a way to create competitive advantage and respond to the fast pace changing environment [2].

Along with that, the concept of Business Process Management (BPM) has been evolving in the past decades. It has its roots on the concept of workflow management (WFM), inspired by the production processes in the manufacturing industry, that is mainly focused on the automation of business processes [1]. BPM, on the other hand, has a wider scope and aims to improve business processes, possible without the use of new technologies [1].

The BPM institute describes BPM as the "definition, improvement and management of a firm's end-to-end enterprise business processes in order to achieve three outcomes crucial to a performance-based, customer-driven firm: 1) clarity on strategic direction, 2) alignment of the firm's resources, and 3) increased discipline in daily operations" [3]. In fact, BPM can be understood as the efforts of an organization to analyse and continually improve its fundamental activities [4].

In the past decades, many maturity models have emerged claiming to guide an organization towards its competitive advantage and, therefore, to its success [5]. The BPM maturity models have the purpose to outline the stages of maturation paths and provide a tool to assess the as-is situation, identify gaps, define improvement initiatives and control the progress [6]. Research appoints that higher levels of maturity in a business process results, among others, in greater effectiveness to reach the defined goals and improving management ability to propose new and higher targets for performance [6].

Among several models, it is possible to highlight the BPM Maturity Model (BPMMM) [7, 8], BPR Maturity Model (BPRMM) [9], Business Process Maturity Model (BPMMFisher) [10], Process Management Maturity Assessment (PMMA) [11], BPO Maturity Model (BPOMM) [5], Process and Enterprise Maturity Model (PEMM) [12], Process Maturity Ladder (PML) [13], Business Process Maturity Model (BPMMOMG) [14] and the Business Process Maturity Model (BPMMLee) [15] [6].

In spite of the fact that many empirical researches indicate that there is a positive correlation between process management and business success [4], and that organizations can improve their performance by adopting a business process orientation [5], research also suggests that only few organizations were able to obtain efficiency gains from the process-oriented transformation programs they have implemented [16].

In fact, there is a common understanding among organizations that the greater the process orientation is, the larger its success. This premise has been guiding many of the investment decisions of organizations in the past years that expect to enhance their competitive advantage by investing significantly in a business process-oriented approach. However, experience shows that this relationship is not always straightforward once there are other variables that might influence the availability of the organization to incorporate the benefits of BPM, as well as its success.

\subsection{Objectives}

The purpose of this research is to provide a contribution to clarify the relationship between the level of BPM maturity and the success of an organization. Specifically, the 
research aims to answer the following question: Is there a relationship between the level of business process management maturity of an organization and its success?

This was done by conducting a qualitative research through a case study within an organization with high perceived BPM maturity level to assess its current maturity and its level of success, as well as to understand the evolution done in the past years regarding process improvements. The data collected was the basis for analysing the results and providing insights about the relationship between the two areas.

\section{Methodology}

To achieve the desired outcome, the work was structured in three phases: 1) conceptualization, where the goal was to, through a literature review, identify the problem and research questions that will guide the study, as well as to define the basis for the research; 2) implementation, where the focus was the implementation of the research according to the inputs provided in the first phase and 3) analysis, where the results were systematized, analysed and discussed in order to answer the research question.

The first step was to conduct an extensive literature review to understand the key concepts related with business process management, business process management maturity and success of an organization.

Once there are many BPM maturity models that can be applied to assess the BPM maturity level of the organizations, a selection of one model was done. For that, an analysis of the existing BPM maturity models and its level of coverage of BPM core areas was conducted. Along with that, and based on the literature review, a conceptual model to measure the success of the organization was defined.

These two inputs were the basis to conduct a qualitative research, implemented through a case study. The selection of this approach and method was done taking into consideration several factors such as the research problem, purpose of the study and its specific goals. The case study was implemented within a shared services organization of an international company who operates in Portugal and has a high perceived process maturity level. This was done through in-depth interviews and documentation analysis.

After collecting all the data, results were systematized in order to bring inputs to support the answer to the research question. These results were analysed, focusing on ensuring the accomplishment of the study objectives, as well as identifying limitations and recommendations for further research.

\subsection{Selection of the BPM maturity model}

The literature review has shown a multiplicity of business process maturity models. Although most of them are based on the CMMI model, they represent different variations of a solution to answer some fundamental questions: (i) how mature are the processes of an organization and (ii) how mature is the organization to manage those processes. There is no best answer to these questions. The key is to understand the needs of the organization and how can the evaluation of its BPM maturity contribute to 
achieve positive outcomes. Based on these factors, organizations should select the model it is considered to best fit their purpose [17].

Even though several BPM maturity models could be used in this research, that would increase significantly the complexity of the assessment tool, which might diminish the company's willingness to participate. Therefore, one of the critical success factors is the selection of one maturity model that best address the purpose of the study.

The selected model should be applicable to any company, despite its dimension and business sector. It is also important that the model is aligned with the key areas of business process management, providing a holistic approach on the maturity of the organization for this subject. To address these issues, an analysis of the coverage of the BPM maturity models through the BPM core areas was undertaken.

The starting point were the models analysed in depth during the literature review phase. Those models were studied in depth in order to understand to which extent they refer to the practices contained within each BPM core area.

A BPM maturity model was considered to have coverage of one BPM core area if they have a dimension, a factor or similar, according to its specific structure, that clearly matches the description and principles of the core area. On the opposite, if no match was possible, the model was considered as having no coverage of the BPM core area. In some situations, where the match was not direct or totally clear, or if it only covers some components of the core area, the model was considered has having partial coverage. The results are presented in Table 1.

With the conducted analysis, it is possible to conclude that there is no BPM maturity model that covers all the BPM core areas. However, some provide greater coverage such as the BPM Maturity Model (BPMMM) of Rosemann \& de Bruin [7]; [18]; [8] and the Business Process Maturity Model (BPMMOMG) of the OMG Group [14]. While the first model lacks on the coverage of the enterprise process management (EPM) core area, the second one lacks on the information systems / information technology (IS/IT) core area.

Once it is intended to evaluate the level of maturity of an organization and not specifically the level of maturity of a process, it is important that the selected model covers the core areas that are under the enterprise perspective. In this context, and despite its limitations, the BPM OMG maturity model was selected.

\subsection{Selection of the measures of organizational success}

The literature review has shown that defining the success of an organization is not straightforward and, in some extent, there is some confusion with the term.

Based on the assumption that the level of success represents in what extent can an organization fulfils its objectives [19], and if we consider that an organization is a complex system composed by several dimensions with specific objectives, a multidimensional approach to the success of an organization should be considered.

In this context, a 5-dimension model to characterize the success of an organization is proposed. 
Table 1. - Results of the analysis of level of coverage of BPM maturity models through the BPM core areas

\begin{tabular}{|c|c|c|c|c|c|c|c|c|c|c|}
\hline & & & & & & & & & \\
\hline & & \multicolumn{9}{|c|}{ BPM Core Areas } \\
\hline \multirow[b]{2}{*}{ Model } & \multirow[b]{2}{*}{$\begin{array}{l}\text { Refer- } \\
\text { ences }\end{array}$} & \multicolumn{7}{|c|}{ Process Perspective } & \multicolumn{2}{|c|}{$\begin{array}{l}\text { Enterprise } \\
\text { Perspective }\end{array}$} \\
\hline & & : & 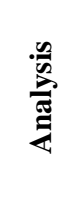 & 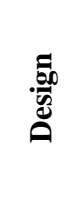 & 壳 & 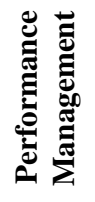 & 竞 & $\stackrel{\infty}{=}$ & 苞 & $\sum_{i=1}$ \\
\hline $\begin{array}{l}\text { BPM Maturity } \\
\text { Model (BPMMM) }\end{array}$ & $\begin{array}{c}\text { [7]; [18]; } \\
\text { [8] }\end{array}$ & $\mathrm{C}$ & $\mathrm{C}$ & $\mathrm{C}$ & $\mathrm{C}$ & $\mathrm{C}$ & $\mathrm{C}$ & $\mathrm{C}$ & $\mathrm{C}$ & $\mathrm{NC}$ \\
\hline $\begin{array}{l}\text { Business Process } \\
\text { Maturity Model } \\
\text { (BPMMFisher) }\end{array}$ & {$[10]$} & $\mathrm{NC}$ & $\mathrm{NC}$ & $\mathrm{NC}$ & $\mathrm{NC}$ & $\mathrm{C}$ & $\mathrm{NC}$ & $\mathrm{C}$ & $\mathrm{PC}$ & $\mathrm{C}$ \\
\hline $\begin{array}{l}\text { Process Management } \\
\text { Maturity Assessment } \\
\text { (PMMA) }\end{array}$ & {$[11]$} & $\mathrm{C}$ & $\mathrm{NC}$ & $\mathrm{C}$ & $\mathrm{NC}$ & $\mathrm{C}$ & $\mathrm{C}$ & $\mathrm{C}$ & $\mathrm{C}$ & $\mathrm{PC}$ \\
\hline $\begin{array}{l}\text { Process and Enter- } \\
\text { prise Maturity Model } \\
(\text { PEMM) }\end{array}$ & {$[12]$} & $\mathrm{C}$ & $\mathrm{C}$ & $\mathrm{C}$ & $\mathrm{NC}$ & $\mathrm{C}$ & $\mathrm{NC}$ & $\mathrm{C}$ & $\mathrm{C}$ & $\mathrm{C}$ \\
\hline $\begin{array}{l}\text { Process Maturity } \\
\text { Ladder (PML) }\end{array}$ & [13] & $\mathrm{PC}$ & $\mathrm{NC}$ & $\mathrm{PC}$ & $\mathrm{NC}$ & $\mathrm{C}$ & $\mathrm{C}$ & $\mathrm{NC}$ & $\mathrm{PC}$ & $\mathrm{NC}$ \\
\hline $\begin{array}{l}\text { BPO Maturity Model } \\
\text { (BPOMM) }\end{array}$ & {$[5] ;[20]$} & $\mathrm{C}$ & $\mathrm{NC}$ & $\mathrm{NC}$ & $\mathrm{NC}$ & $\mathrm{C}$ & $\mathrm{NC}$ & $\mathrm{C}$ & $\mathrm{C}$ & MC \\
\hline $\begin{array}{l}\text { Business Process } \\
\text { Maturity Model } \\
\text { (BPMMOMG) }\end{array}$ & {$[14]$} & $\mathrm{C}$ & $\mathrm{C}$ & $\mathrm{C}$ & $\mathrm{C}$ & $\mathrm{C}$ & $\mathrm{C}$ & $\mathrm{NC}$ & $\mathrm{C}$ & $\mathrm{C}$ \\
\hline
\end{tabular}

C - Covers; PC - Partially Covers; NC - No Cover

Fulfilment of mission. Mission statements are one of the cornerstones of strategy definition, providing a sense of purpose and establishing the direction of an organization [21]. Considering that the mission statement of an organization represents its ultimate goal, it cannot be disregarded the fulfilment of the mission as a dimension to measure organizational success.

Financial performance. Financial performance has been one of the most traditional perspectives to measure the success of an organization. Although the fact that other perspectives have been included in measuring organizational performance and success, the financial perspective is still widely used in the literature, as well as in business practice, and cannot be discarded [22-26]. 
Market performance. Along with financial performance, market performance has been widely considered in measuring organizational performance, providing an external point of view $[22,23,26]$. In fact, besides the importance of having a financially well performed company, it is also relevant to consider how the company is performing in the market against its competitors, as well as to which extent it is satisfying its customer needs [23, 27, 28].

Internal performance. Internal performance refers to the internal aspects such as processes, human capital, corporate culture as well as other internal practices that allow companies to develop and sustain its competitive advantage. The Balanced Scorecard [22] introduces this variable through the internal and the learning \& growth perspective. The DMP approach also reflects the internal performance through its people development and process dimensions [23]. Also, Pickle \& Frielander [29] refer to one of the most important stakeholders within a company: the employees. Therefore, internal performance is considered to be related with human capital management issues, quality issues as well as cultural issues.

Sustainability. Another view on company's success relates to the sustainability of the organization. Organizations perform their activities in a given environment, influencing it. In this context, the concept of corporate sustainability has been gaining importance [30-32]. However, the sustainability concept within the business context does not have a single definition. The study conducted by Lankoski [33] identifies different usages of the concept highlighting the concept of sustainability as the long term viability of the business and sustainability as corporate social responsibility. Both of these approaches to the sustainability concept will be considered in this study.

For each of the five dimensions proposed to characterize organizational success, some categories were defined based on the literature review. The purpose of defining categories is to provide a more consistent logical framework for measuring success. Also, defining categories helps with the process of selecting metrics for measurement, allowing it to be more focused and straightforward. In this context, for each category, one or two measures were selected, as presented in Table 2. The number of measures was not too extensive, so the research would not be highly complex, increasing willingness to participate from the company. Besides ensuring that the proposed metrics were aligned with the dimension to be evaluated, three key aspects were considered when selecting the metrics for each category: the obtainability of quantitative or quantifiable data, availability of information in the company and relevance of metrics.

Furthermore, the metrics should be simple, understandable and useful as a tool [34]. 
Table 2. - Dimensions, categories and metrics to measure organizational success

\begin{tabular}{|c|c|c|c|}
\hline Dimension & Category & Metric & References \\
\hline \multirow{5}{*}{$\begin{array}{l}\text { Fulfilment of } \\
\text { Mission } \\
\text { Financial Per- } \\
\text { formance }\end{array}$} & - & Perception of managers & [21] \\
\hline & Growth & Income growth rate & [34] \\
\hline & Profitability & Net profit margin & {$[28,35]$} \\
\hline & Efficiency & Return on equity & {$[23,28,35]$} \\
\hline & & Return on assets & {$[23,28,35]$} \\
\hline \multirow{3}{*}{$\begin{array}{l}\text { Market Perfor- } \\
\text { mance }\end{array}$} & Market position & Market share & {$[23,27,28,35]$} \\
\hline & & Sales growth rate & {$[23,28,35]$} \\
\hline & $\begin{array}{l}\text { Customer satis- } \\
\text { faction }\end{array}$ & $\begin{array}{l}\text { Level of customer satisfac- } \\
\text { tion }\end{array}$ & [27] \\
\hline \multirow{5}{*}{$\begin{array}{l}\text { Internal Perfor- } \\
\text { mance }\end{array}$} & Human capital & Turnover rate & [35] \\
\hline & & Employee growth rate & {$[25,28,35]$} \\
\hline & $\begin{array}{l}\text { Organizational } \\
\text { culture }\end{array}$ & $\begin{array}{l}\text { Perception of managers on } \\
\text { how strong the culture is }\end{array}$ & [36] \\
\hline & $\begin{array}{l}\text { Quality \& risk } \\
\text { management }\end{array}$ & $\begin{array}{l}\text { Implementation of opera- } \\
\text { tional internal audits }\end{array}$ & [37] \\
\hline & & $\begin{array}{l}\text { Implementation of risk man- } \\
\text { agement procedures }\end{array}$ & [37] \\
\hline \multirow[t]{3}{*}{ Sustainability } & Longevity & $\begin{array}{l}\text { Number of years company is } \\
\text { in business }\end{array}$ & [35] \\
\hline & $\begin{array}{l}\text { Corporate social } \\
\text { responsibility }\end{array}$ & $\begin{array}{l}\text { Investment in CSR initia- } \\
\text { tives on total revenue }\end{array}$ & [38] \\
\hline & Innovation & $\begin{array}{l}\text { Investment in R\&D and self- } \\
\text { innovation }\end{array}$ & [38] \\
\hline
\end{tabular}

\subsection{Case study implementation}

Selecting the best approach and methodology is usually one of the most challenging aspects when implementing a research.

As previously mentioned, there is a lack of research between the relationship between BPM maturity and the success of the organizations and the purpose of this research is to provide insights and to better understand this relationship, which could be a starting point for further research.

According to Darke, Shanks, \& Broadbent [39], case study has been one of the most used methods to implement a qualitative research in information systems (IS) research. It assumes particular relevance when it is used to investigate a complex phenomenon 
that rely on several evidences. Hughes \& McDonagh [40] also refer its popularity in IS research and refer it as a powerful method when implementing an exploratory research as it allow to get higher richness of data. Trkman [4] also refers that case study methods can be used when we are still trying to understand or discover a problem within an emerging area.

In spite of its limitations $[39,40]$, it is considered as suitable to be used when trying to relate information systems innovation and organizational contexts [39], which fits the scope of this research. In this context, an exploratory research based on a qualitative approach with case study was the selected method.

The research was implemented within a global company that operates in the energy sector and has an operation in Portugal. The starting point to identify a company was the list of the five hundred (500) bigger companies in Portugal, published annually by Exame magazine, a magazine leader in the business sector. Within the list, the criteria applied to select the company were the high perceived process maturity level, the fact that has an operation in Portugal and its willingness to cooperate.

The selected company operates in Portugal for one hundred and twelve (112) years in several areas such as energy, infrastructures and mobility. It is also an important hub for providing services to other companies and locations within the same business group through its shared services organization.

Considering the existent body of knowledge and literature available in this area, it is possible to understand that business process management practices have been assuming particular importance in the shared services area.

Shared services could be understood as the support functions from different departments that are consolidated into a specific organizational entity that aims to provide these services in an efficient and effective way. This services usually include areas such as human resources, finance and procurement [41, 42].

Establishing a shared service organization has been an approach that many companies have been following in the past decades as a way to allow them to focus on its business, improve quality, reduce costs and develop new capabilities, among other benefits [42].

Considering the benefits of a high business process management maturity and business process orientation, along with the expected benefits from implementing a shared services area, it is possible to identify similarities regarding efficiency, quality and continuous improvement which raises the importance of conducting this study within a shared service organization.

\section{$3 \quad$ Results}

\subsection{BPM Maturity Analysis}

The assessment of the current BPM maturity level, based on the BPM OMG Maturity Model, allow to portrait the current situation of the organization regarding its process management practices. This can be used to identify constraints and improvement 
initiatives that can be undertaken to ensure that the organization captures and incorporates the benefits of having a high process orientation.

Each maturity level, except the first one, have a set of defined process areas in a total of thirty (30) process areas. The maturity level is achieved when the goals of the process areas are accomplished. Process areas can be related with four main cornerstones: organization, work unit, product \& service offering and improvements [14].

Based on the interview conducted with the process manager, as well as from the analysis of the documentation provided, it was possible to establish what was the level of fulfilment of each process area hence each maturity level. To do that, and due to the fact that a process area can only be considered as accomplished if its specific goals are achieved [14], an analysis per specific goal was undertaken. For each specific goal, a score between 0 and 1 was attributed. The accomplishment level of each process area is given by the average of the scoring of each specific goal.

Results suggest that the first three maturity levels - initial, managed and standardized - are achieved once each process area and its related specific goals are fulfilled.

The fourth maturity level - predictable - is partially achieved with an accomplishment level of $66 \%$. This is mainly due to the fact that the quantitative management of the processes is still done in an incipient way without robust and statistically managed approaches to establish predictable results. In fact, the process area with lower score $(0,33$ out of 1,00$)$ is the quantitative process management $(\mathrm{QPM})$, followed by the quantitative product and service management (QPSM) $(0,50$ out of 1,00$)$.

The fifth and last maturity level - innovating - is also not completely achieved, with an accomplishment level of $82 \%$. Although the organization has established several practices for innovation and continuous improvement, there is still a lack of understanding of which are the direct quantitative impacts of each improvement implemented. These outcomes are comprehensible if we consider the results from the fourth maturity level where one of the least rated areas is associated with the lack of a quantitative management approach.

Also, in spite of the quality management system in place that promotes a high process management maturity, the focus on individual process performance and workgroup process performance is limited as there is no specific practices in place that address these components. This is reflected in the continuous capability improvement area $(\mathrm{CCI})$ that has the lowest score on this maturity level $(0,25$ out of 1,00$)$.

As a conclusion, it is possible to state that the studied organization has a high BPM maturity level. As the model states that an organization can only achieve a maturity level if it meets the requirements associated with the previous maturity level [14], the maturity of the studied organization is established at level 4 - predictable.

\subsection{Process improvements and impacts}

The second area of the study is focused on understanding what improvements have been made on the organization's processes, in the past years, and what were the results of those improvements, in a qualitative and, if possible, quantitative way. 
Shared services organizations seek to provide cost savings, increased efficiency and the development of new capabilities in the environment they are established [42]. To leverage their ability to fulfil its goals, they have been heavily investing in information systems and technology such as enterprise resource planning (ERP), self-service portals and automation tools [41]. This has been one of the drivers of the organization, that has been investing on the digital transformation of the value chain including areas such as master data, customer order management, purchase to pay and cash management. This is aligned with the trends of the shared service organizations such as digital transformation and service automation as appointed by Lacity \& Willcocks [41].

\subsection{Characterizing the success of the organization}

The third component of the study aims to characterize the success of the organization. This was done according to the proposed model that is structured in five areas: (i) fulfilment of mission, (ii) financial performance, (iii) market performance, (iv) internal performance, and (v) sustainability.

Fulfilment of Mission. Fulfilment of mission is evaluated through the perception of the manager regarding to which extent is the mission of the organization being accomplished. This input was collected in the interview conducted to the process manager and the result is that it is confirmed that the organization is accomplishing the purpose for what it was created for.

Financial performance. Although a shared service organization does not pursue higher profits but rather efficiency and optimization, this variable could not be disregarded from analysis.

In spite of the fact that financial performance has not been improving, according to growth and profit metrics, the organization is stable from the financial point of view as it provides significant income every year. Profit rate is not very high but, if we consider that shared services organization do not pursue profit, these values are as expected.

Two additional metrics for measuring financial performance were proposed in the model: return on equity and return on assets. However, this data was not possible to obtain from the organization.

If we consider the specific context of the organization, an important metric arises: savings. As previously mentioned, a shared services organization pursues optimization which, in the end, might be reflected as savings. This metric has been evolving positively in the past years, demonstrating the focus on efficiency and optimization.

Market performance. To asses this variable, two perspectives are appointed in the model: one related with competition and one related with customer satisfaction.

The studied organization does not operate in an intensive competitive market as the shared service area provides business services to other organizations within the same business group. Therefore, market share is not a relevant metric in this context. 
On the other hand, sales growth metric allows to understand how the organization has been evolving in terms of providing more or new services to its customers. According to the data provided, this has been evolving positively in the last years, which shows a positive trend regarding service provision to customers.

Customer satisfaction is also a very important metric. The results show a high level of customer satisfaction throughout the time, with the lowest score of 8,59 out of 10 achieved in 2017. The score has been consistently higher in the Portuguese organization when comparing to other locations that provide similar services.

Internal Performance. The defined model to measure the success of the organization also considers the internal perspective concerning human capital, corporate culture and quality management practices. The first metric, turnover rate, was between $10 \%-16 \%$ in the last three years. These values are aligned with the industry practices [43].

The number of employees has been increasing in the past years, with special attention between 2018 and 2019 where a big increase was verified, along with the increase of the service volume

Organizational culture was evaluated through the perception of manager regarding on how strong the culture is. The organization shows a well-established culture, with a set of principles, values and guidelines transmitted to the employees that ensure their implementation in their day-to-day work.

Regarding quality, two metrics were analysed: the implementation of internal audits and the implementation of risk management procedures. Both are visible in the company.

Sustainability. This component, along with the internal performance, allows to complement the traditional perspective on the success of an organization, providing insights on how the company lives in an increasingly complex environment.

The first indicator of sustainability is the longevity of the organization, meaning the number of years that it is performing its business. The studied organization has more than a decade in business and has been growing significantly during this period in terms of clients, employees and business model which shows its consolidation as a shared service organization.

The second indicator refers to the capacity of the organization to give back to the community and is focused on the investment in corporate social responsibility initiatives. Corporate social responsibility has been an area of importance in the organization which can be seen by the investment done in the past years.

The third indicator is related with the investment in R\&D and self-innovation. Due to the specificity of the organization and its governance, it was not possible to obtain this information focused only in the shared services organization. 


\section{Discussion}

The results from the BPM maturity assessment allow to understand that the organization has established itself on the maturity level 4, even though it had already accomplished some process areas from maturity level 5.

Although the organization does not have implemented a BPM model, it is able to achieve a good BPM maturity level due to the existence of a high focus on quality management. In fact, through the analysis conducted, it is possible to conclude that the high level of BPM maturity is based on nine cornerstones:

1. The existence of a solid and consolidated quality management system that was implemented since the organization was established. The quality management system includes a systematic assessment and auditing process to ensure the compliance with the defined guidelines. The assessment provides a score that reflects the maturity of the quality management practices which allows organization to define and implement a roadmap, as well as to compare itself with other similar organizations within the same business group. To show the importance of this quality management system to executive management, one of the annual performance targets defined by the organization is the score achieved in these assessments.

2. The implementation, within the scope of the quality management system, of several approaches and methodologies to identify and treat the non-conformances as well as to establish process improvement initiatives. In this context it is important to highlight the 8D tool and FMEA (failure mode and effect analysis). 8D tool allows the organization to have a reactive response to non-conformances and issues that arise in their operation, allowing it to be registered, tracked, solved and communicated. FMEA analysis, on the other hand, allows the organization to have a proactive response to potential risks, as well as to identify and implement improvement activities in the processes.

3. The fact that processes and work instructions are documented and available in the organization, reflecting the work that needs to be conducted by each work unit according to the requirements established in the internal service agreements (ISAs).

4. The establishment of internal service agreements (ISAs) with the customers that reflect the requirements for the service, as well as the key performance indicators (KPIs) that represent the performance agreements. They are also an important instrument to conduct the capacity planning process to ensure the alignment between demand and resources.

5. The application of a change request process that documents the changes that are requested to a service, analyses them with the support from a business case and an impact analysis and implements them in a structured way, agreed by the relevant stakeholders.

6. The definition of organizational targets, drilled down to the different organizational levels, from top management to individuals, through the performance management program, that promote the alignment of business activities and drives the implementation of improvement activities. 
7. The promotion of an open error culture, where errors are accepted and treated with a positive approach, as well as a continuous improvement system, that promotes innovation, best practice sharing and the implementation of improvement measures.

8. The recent transformation to an organization focused on end-to-end processes that promote coordination, alignment and synergies throughout the work units and organizational levels.

9. The high technological maturity, once most of the processes are supported by information systems and technology to promote efficiency and accountability.

This is aligned with the findings from Feldbacher, Suppan, Schweiger, \& Singer [44] that establish that service companies reach an high maturity level than manufacturer ones. Also, companies that are active in the IT sector were shown to have a higher maturity level than companies from other industries.

The next steps to climb in the maturity ladder, according to the BPM OMG maturity model [14] are related with increasing the focus on managing the individual processes and workgroup processes in a more quantitative and statistically way, in order to achieve predictable results.

The organization is aware of the steps to be done and has already started to implement tools to improve the maturity level as it recognizes that it will allow to increase efficiency, reduce costs and improve client satisfaction. This is aligned with the findings from several authors that refer that organizations constantly seek to improve their maturity level as they believe greater maturity leads to greater performance $[8,10,11]$.

Organization is also conscious of the importance of technology as a catalyst to promote their process management maturity. Although the technology maturity can be perceived as high, there is still a path to pursue towards a digital transformation of the operations. In this context, the organization has been highly investing in projects that focus on process automation, robotization and data analytics solutions.

The projects already implemented in this context have been providing significant results in terms of improved productivity, end-to-end integration, increased data quality, manual effort reduction with impact in the occurrence of errors, cycle time reduction and increased customer satisfaction. It also allowed the organization to improve its monitoring activities, establishing a more robust and accountable continuous improvement system, as well as to implement workforce upskilling programs. This was key to establish the organization as a successful shared service provider and is coherent with the appointed benefits of adopting a BPM approach.

Looking to the dimensions defined to characterize the success of the organization, they can be impacted by some of the appointed benefits from a high BPM maturity.

The main benefits from a high BPM maturity, leveraged by the usage of information systems and technology, that were identified through the study, can be grouped in six building blocks: (i) improve productivity; (ii) reduce costs; (iii) error and risk prevention; (iv) upskilling; (v) high agility; and (vi) knowledge retention.

According to the conducted literature review, a high BPM maturity allow to increase productivity and efficiency. If the organization improves productivity, this might lead to customer satisfaction, especially in a shared services organization where the customers pursue an increase in efficiency. Higher customer satisfaction will promote the 
consolidation of the organization in the market as it will allow a growth of sales. It is also a driver of growth as higher customer satisfaction might lead to income increase.

One of the impacts noted from a high BPM maturity is also cost reduction. This might influence several dimensions of the success of the organization. If we reduce costs, we are able to increase our net profit margin. On the other hand, as shared services organizations aim to provide cost effectiveness to their customers, this will also impact the customer satisfaction, hence contributing to strengthen the market position and possible revenue increase. Although this relationship is not always possible to verify from the literature review, this was pointed as a consequence of the investment of the organization in several process improvement projects, especially due to the context it operates.

Also, with cost reduction, organizations might have higher availability to invest in corporate social responsibility activities hence contributing to the sustainability component of the success of an organization.

Error and risk prevention are also appointed as impacts from a high BPM maturity. In fact, if the organization has a process-oriented culture in terms of people, processes and technology, it is more likely to have a proactive posture towards risk and potential errors. This directly impacts the quality of the delivered products and services hence influencing customer satisfaction in a positive way. Customer satisfaction, on the other hand, might lead to a stronger market position and revenue growth. Also, if the organization manages issues and risks properly, the negative impact of unwanted events might diminish, helping the organization deal with unexpected costs, hence impacting profit.

Another appointed benefit relates with the upskilling of employees. With process improvements focused on automation, employees do not need to perform routine tasks on a regular basis, which allow them to conduct higher value activities. This might represent an increase in the available capacity that could allow organization to gather new customers and increase its revenue.

Also, the available capacity could be shifted to conduct new tasks, more challenging and rewarding, that might lead to higher employee retention and commitment or even employee growth, hence lower turnover rate. Companies with less employee rotation have shown to have strengthen organizational cultures $[45,46]$ so it is possible to consider that lower turnover rate impacts positively the organizational culture. Employee turnover, on the other hand, is shown to affect growth, profitability and customer satisfaction [46].

High agility is also appointed as one of the benefits of a high BPM maturity has streamlined processes and less efforts on error detection and solving allow organizations to respond faster to customer needs. This improves customer satisfaction, strengthen market position, as well as increase potential income.

Knowledge retention is also an important point when it comes to BPM maturity. With documented processes, requirements and changes, the organization is promoting its knowledge retention which leads to a strengthened organizational culture and employee retention. A lower turnover rate, on the other hand, has impacts related with growth, profitability and customer satisfaction. 
Besides the direct relations between the BPM maturity benefits and the success of the organization, other relationships should be highlighted in a broader sense. Experience shows that an organization that is growing, that is profitable and that has a wellestablished position in the market is likely to be sustainable and have greater longevity. This will impact the fulfilment of the mission as an organization, to accomplish the purpose for which was created, needs to have these four pillars well established and solid. These relationships are summarized in Figure 1.

In fact, the benefits from a high BPM maturity influence, in a positive way, the key dimensions of growth, profitability, market position, customer satisfaction, human capital, organizational culture, quality \& risk management and corporate social responsibility that, on their turn, contribute to the longevity of the organization and, consequently, to the fulfilment of its mission. On the other hand, the success of an organization is something complex and cannot be explained only by the high BPM maturity as there are other variables, internal and externals, that influence the ability of an organization to be successful.

BPM Maturity Benefits

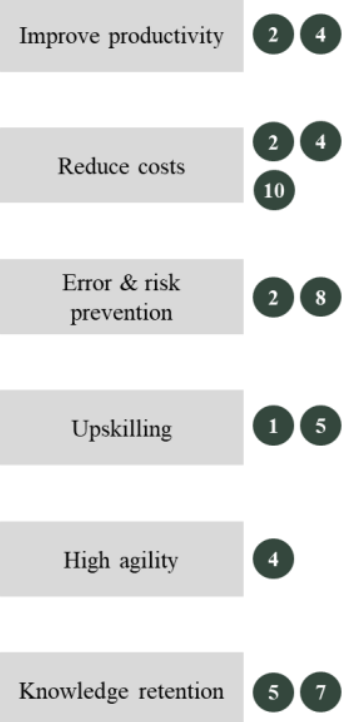

\section{Organizational Success}

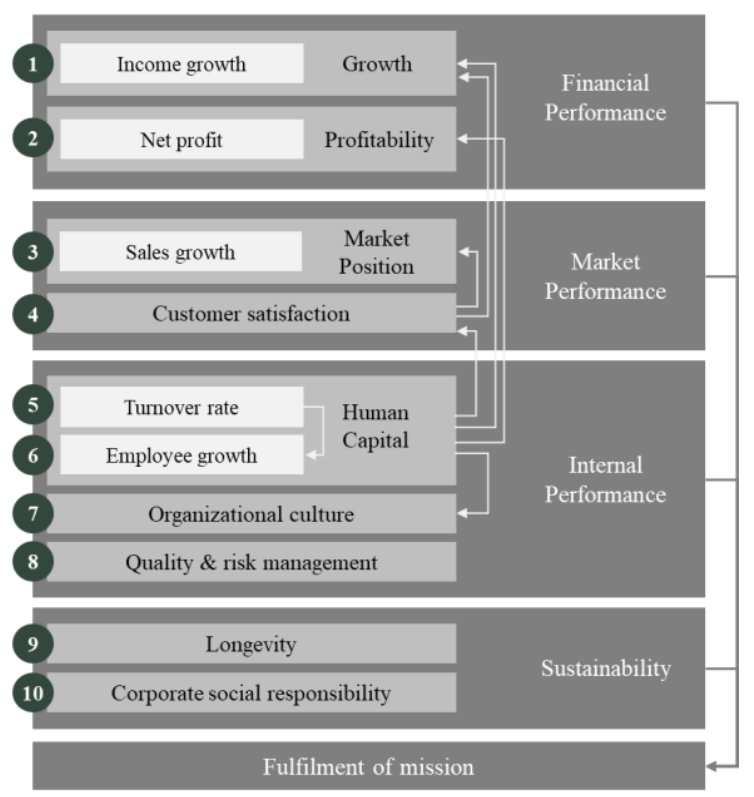

X Relationship between BPM maturity impact and organizational success $\longrightarrow$ Relationship between organizational success dimensions

Fig. 1. - Established relationships between BPM maturity and organizational success 


\section{Conclusion}

Business process management has been assuming greater importance in the past years, as organizations continuously seek to achieve greater efficiency and effectiveness to leverage its competitive advantage in an increasingly complex environment.

The purpose of the study was to understand if there is a relationship between the level of business process management maturity and the success of an organization.

The research started with a literature review to understand the key concepts related with business process management, business process management maturity and success of an organization.

Once there are many BPM maturity models that can be applied to assess the BPM maturity level of the organizations, a selection of one model was done through an analysis of the existing BPM maturity models and its level of coverage of BPM core areas. Along with that, and based on the literature review, a conceptual model to measure the success of the organization was defined.

These two inputs were the basis to conduct a qualitative research, implemented through a case study, grounded on in-depth interviews and documentation analysis, within a shared services organization of an international company who operates in Portugal and has a high perceived process maturity level. The case study was structured in three areas: (i) assessment of the current BPM maturity level, based on the BPM OMG maturity model; (ii) process improvements and its impacts; and (iii) characterization of the success of the organization.

The results from the BPM maturity assessment allow to understand that the organization has established itself on the maturity level 4, even though it already had fully accomplished some process areas from maturity level 5. Although the organization does not have implemented a BPM model, it is able to achieve a good BPM maturity level due to a strong focus on quality management and a high technological maturity.

The organization is aware of the steps to be done to climb the maturity ladder as it recognizes that it will allow to increase efficiency, reduce costs and improve client satisfaction. It is also conscious of the importance of technology as a catalyst to promote their process management maturity. In this context, the organization has been highly investing in projects that focus on process automation, robotization and data analytics solutions.

The projects already implemented, have been providing significant results can be grouped in six building blocks: (i) improve productivity; (ii) reduce costs; (iii) error and risk prevention; (iv) upskilling; (v) high agility; and (vi) knowledge retention.

This building blocks were shown to affect some dimensions of organizational success such as customer satisfaction, net profit, turnover, innovation, quality \& risk management, income growth, organizational culture, among others. Those dimensions are key to establish a good financial, market and internal performance, as well as to promote the sustainability of the organization allowing it to fulfil its mission.

In this context, results suggest a positive relationship between the BPM maturity and the success of the organization, from a qualitative perspective. In fact, the research shows that an organization that has a high BPM maturity and has a high focus on process improvement is able to incorporate several benefits that leverage its ability to be 
more successful. However, the success of an organization is something complex and cannot be explained only by the high BPM maturity as there are other variables, internal and externals, that influence the ability of an organization to be successful.

Nevertheless, the research provides insights on how the relationship between process maturity and performance and success of an organization might be established which is important for the decision-making process of organizations when it comes to invest in BPM projects.

\subsection{Limitations of the study and recommendations for further research}

In spite of the fact that the research goals were achieved, there are some limitations of the study that should be pointed, along with some recommendations for future research.

The research was conducted through a case study within a shared service organization. Although this methodology provides deep insights on how organization has established its BPM practices, it lacks on comparability with other organizations. A suggestion for further research could be to expand the range of studied organizations. Other suggestion could be to study, with a quantitative approach, several organizations that operate in different business sectors allowing to collect statistical data that could corroborate the assumption that higher maturity levels lead to greater success.

The BPM maturity assessment itself also has some limitations to be pointed. The assessment was designed to ensure the willingness to participate from the organization and, therefore, was conducted up to the level of the specific goals within each process area and did not include the specific practices.

The fact that the BPM assessment was done through in-depth interviews also presents a limitation. By collecting data through interviews, we are, in some extent, exposed to the subjectivity of the answers from our interviewed. Although this risk was reduced by conducting a documentation analysis, some subjectivity might still exist.

Regarding definition of success, the framework that was established was intended to be the most generic as possible, in order to be applied to different organizations regardless of their business and context. However, by doing this, some of the specificities of the organization might have been disregarded.

Concerning the results of the study, two major limitations are ought to be appointed. First, the established relationship between BPM maturity and the success of the organization is qualitative and lacks quantitative data to corroborate the findings. Furthermore, it does not allow to establish the strength of the identified relationships. Future research should rely on establishing a quantitative relationship between these two dimensions in order to validate the achieved results. Second, the established relationships only consider the dimensions of success that were possible to analyse within the company. Additional measures related with efficiency and market position should be considered in further researches. 


\section{References}

1. Van Der Aalst, W.M.P., La Rosa, M., Santoro, F.M.: Business process management: Don't forget to improve the process! Bus. Inf. Syst. Eng. 58, 1-6 (2016). https://doi.org/10.1007/s12599-015-0409-x

2. Willaert, P., Bergh, J. Van Den, Willems, J., Dirk, P.: The process-oriented organisation: a holistic view developing a framework for business process orientation maturity. Bpm 2007, Lncs 4714. 1-15 (2007). https://doi.org/10.1007/978-3-540-75183-0_1

3. Rock, G., Dwyer, T.: What is BPM Anyway? Business Process Management Explained, http://www.bpminstitute.org/

4. Trkman, P.: The critical success factors of business process management. Int. J. Inf. Manage. 30, 125-134 (2010). https://doi.org/10.1016/j.ijinfomgt.2009.07.003

5. McCormack, K., Willems, J., van den Bergh, J., Deschoolmeester, D., Willaert, P., Indihar Štemberger, M., Škrinjar, R., Trkman, P., Bronzo Ladeira, M., Paulo Valadares de Oliveira, M., Bosilj Vuksic, V., Vlahovic, N.: A global investigation of key turning points in business process maturity. Bus. Process Manag. J. 15, 792-815 (2009). https://doi.org/10.1108/14637150910987946

6. Röglinger, M., Pöppelbuß, J., Becker, J.: Maturity models in business process management. Bus. Process Manag. J. 18, 328-346 (2012). https://doi.org/10.1108/14637151211225225

7. Rosemann, M., de Bruin, T., Hueffner, T.: A Model for Business Process Management Maturity. ACIS 2004 Proceedings.Paper 6. 1-7 (2004)

8. Rosemann, M., Bruin, T. De: Towards a Business Process Mangement Maturity Model. ECIS 2005 Proc. Thirteen. Eur. Conf. Inf. Syst. 26-28 (2005). https://doi.org/10.1109/EUROMICRO.2007.35

9. Maull, R.S., Tranfield, D.R., Maull, W.: Factors characterising the maturity of BPR programmes. Int. J. Oper. Prod. Manag. 23, 596-624 (2003). https://doi.org/10.1108/01443570310476645

10. Fisher, D.M.: The business process maturity model: a practical approach for identifying opportunities for optimization. Bus. Process Trends. 9, 11-15 (2004)

11. Rohloff, M.: Process Management Maturity Assessment. AMCIS 2009 Proc. 631-642 (2009)

12. Hammer, M.: The Process Audit, (2007)

13. Harmon, P.: Evaluating an Organization's Business Process Maturity. Bus. Process Trends. 2, 1-11 (2004)

14. Weber, C.; Curtis, B.; Gardiner, T.: Business Process Maturity Model (BPMM) Version 1.0. (2008)

15. Lee, J., Lee, D., Kang, S.: An Overview of the Business Process Maturity Model (BPMM). 4537, (2007). https://doi.org/10.1007/978-3-540-72909-9

16. Alibabaei, A., Bandara, W., Aghdasi, M.: Means of Achieving Business Process Management Success Factors. Proc. 4th Mediterr. Conf. Inf. Syst. 25-27 Sept. 2009 , Athens Univ. Economics Business, Athens. 25-27 (2009). 
https://doi.org/Article

17. Van Looy, A., Backer, M. De, Poels, G., Snoeck, M.: Choosing the right business process maturity model. Inf. Manag. 50, 466-488 (2013). https://doi.org/10.1016/j.im.2013.06.002

18. Rosemann, M., de Bruin, T.: Application of a Holistic Model for Determining BPM Maturity. Proc. AIM Pre-ICIS Work. Process Manag. Inf. Syst. 46-60 (2004)

19. Miller, D., Peter, H.: Archetypes of Strategy Formulation. Manage. Sci. 24, 921-934 (1978)

20. Lockamy, A., Childerhouse, P., Disney, S.M., Towill, D.R., McCormack, K.: The impact of process maturity and uncertainty on supply chain performance: An empirical study. Int. J. Manuf. Technol. Manag. 15, 12-27 (2008). https://doi.org/10.1504/IJMTM.2008.018237

21. Pinho, C., Silva, A.M., Macedo, I.M.: Revisiting the link between mission statements and organizational performance in the non-profit sector: The mediating effect of organizational commitment. Eur. Manag. Jour. 34, 36-46 (2016). https://doi.org/10.1016/j.emj.2015.10.003

22. Kaplan, R.S., Norton, D.P.: The Stategy-Focused Organization: How Balanced Scorecard Companies Thrive in the New Business Environment. Harvard Business School Press (2001)

23. Maltz, A.C., Shenhar, A.J., Reilly, R.R.: Beyond the balanced scorecard: Refining the search for organizational success measures. Long Range Plann. 36, 187-204 (2003). https://doi.org/10.1016/S0024-6301(02)00165-6

24. Crumpton-Young, L.L., Ferreras, A.M.: The measure of success. Ind. Manag. (2013)

25. Leković, B., Marić, S.: Measures of small business success / performance importance, reliability and usability. Industrija. 43, 7-26 (2015). https://doi.org/10.5937/industrija43-7209

26. Keerthika, D., Alagarsamy, S.: A Multiple Measure of Organizational Performances and its Effect on Distinctive Marketing Competencies : An Empirical Study of India and the Maldives. J. Manag. Mark. Rev. 3, 129-142 (2018)

27. Clark, B.: Measuring marketing performance: research, practice and challenges. In: Neely, A. (ed.) Business Performance Measurement: Unifying Theories and Integrating Practice, Second edition. pp. 36-63. Cambridge University Press (2007)

28. J. Richard, P., M. Devinney, T., S. Yip, G., Johnson, G.: Measuring Organizational Performance : Towards Methodological Best Practice $\dagger$. J. Manage. 35, 718-804 (2009). https://doi.org/10.1177/0149206308330560

29. Pickle, H., Frielander, F.: Seven Societal Criteria of Organizational Success. Pers. Psychol. 20, 165-178 (1967). https://doi.org/10.1111/j.17446570.1967.tb02277.x

30. Linnenluecke, M.K., Griffiths, A.: Corporate sustainability and organizational $\begin{array}{llllll}\text { culture. J. World } & \text { Bus. 45, 357-366 }\end{array}$ https://doi.org/10.1016/j.jwb.2009.08.006

31. Alexandre, A., Francisco, A.C. De: Organizational Sustainability Practices: A 
Study of the Firms Listed by the Corporate Sustainability Index. Sustainability. 10, (2018). https://doi.org/10.3390/su10010226

32. Asemah, E.S., Okpanachi, R.A., Edegoh, L.O.N.: Business Advantages of Corporate Social Responsibility Practice: A Critical Review. New Media Mass Commun. 18, (2013). https://doi.org/10.4028/www.scientific.net/MSF.879.1019

33. Lankoski, L.: Alternative conceptions of sustainability in a business context. J. Clean. Prod. 139, 847-857 (2016). https://doi.org/10.1016/j.jclepro.2016.08.087

34. Székely, F., Knirsch, M.: Responsible Leadership and Corporate Social Responsibility : Metrics for Sustainable Performance. Eur. Manag. J. 23, 628-647 (2005). https://doi.org/10.1016/j.emj.2005.10.009

35. Murphy, G.B., Trailer, J.W., Hill, R.C.: Measuring Performance in Entrepreneurship. J. Bus. Res. 2963, 15-23 (1996)

36. Garmendia, J.A.: The Impact of Corporate Culture on Company Performance, (2004)

37. Shin, W.S., Dahlgaard, J.J., Dahlgaard-park, S.M., Kim, M.G.: A Quality Scorecard for the era of Industry 4.0. Total Qual. Manag. Bus. Excell. 29, (2018). https://doi.org/10.1080/14783363.2018.1486536

38. Kao, E.H., Yeh, C., Wang, L., Fung, H.: The relationship between CSR and performance: Evidence in China. Pacific-Basin Financ. J. 51, 155-170 (2018). https://doi.org/10.1016/j.pacfin.2018.04.006

39. Darke, P., Shanks, G., Broadbent, M.: Successfully completing case study research combining rigour, relevance and pragmatism. Inf. Syst. J. 273-289 (1998)

40. Hughes, J., McDonagh, J.: In defence of the case study methodology for research into strategy practice. Irish J. Manag. 36, 129-145 (2017). https://doi.org/10.1515/ijm-2017-0013

41. Lacity, M., Willcocks, L.: Robotic Process Automation: Transformation Lever for Shared Services. Credit Financ. Manag. Rev. 22, 16-45 (2016)

42. Fielt, E., Bandara, W., Miskon, S., Gable, G.: Exploring shared services from an is perspective: A literature review and research agenda. Commun. Assoc. Inf. Syst. 34, 1001-1040 (2014)

43. Deloitte: Global Shared Services 2017 Survey Report. (2017)

44. Feldbacher, P., Suppan, P., Schweiger, C., Singer, R.: Business Process Management : A Survey among Small and Medium Sized Enterprises Business Process Management : A Survey among Small and Medium Sized Enterprises. Presented at the (2016)

45. Bosomtwe, T.E., Obeng, B.: The Link between Organizational Culture and Turnover Intention among Employees in Ghana. Int. J. Contemp. Res. Rev. 9, 20951-20958 (2018). https://doi.org/10.15520/ijcrr/2018/9/08/566

46. Mutua, C.M., Simba, F.T.: Effect of Organisational Culture on Employee Turnover: A case Study of Technical University of Mombasa. J. Manage. 4, 1-14 (2017) 